\title{
Publication of reviews and papers based on the proceedings of the XX Mendeleev Congress on General and Applied Chemistry is planned to be continued in issues 10 and 11, 2017:
}

- A. V. Marikutsa, N. A. Vorob'eva, M. N. Rumyantseva, and A. M. Gas'kov "Active sites on the surface of nanocrystalline semiconductor oxides $\mathrm{ZnO}$ and $\mathrm{SnO}_{2}$ and gas sensitivity" (review)

- M. V. Talanov, V. M. Talanov, and V. B. Shirokov "Unique hyperkagome atomic order in geometrically frustrated iridium spinel-like structures" (review)

- A. A. Malygin, A. A. Malkov, and E. A. Sosnov "Structure size effects and their application in core-nanoshell systems synthesized by molecular layering" (review)

- T. S. Svalova, N. N. Malysheva, and A. N. Kozitsina "Structure of the receptor layer in electrochemical immunosensors. Modern trends and prospects of development" (review)

- V. B. Sokolov, G. F. Makhaeva, A. Yu. Aksinenko, V. V. Grigor'ev, E. F. Shevtsova, and S. O. Bachurin "Targeted synthesis and biological activity of polypharmacophoric agents for the treatment of neurodegenerative diseases" (review)

- D. S. Druzhilovskii, A. V. Rudik, D. A. Filimonov, T. A. Gloriozova, A. A. Lagunin, A. V. Dmitriev, P. V. Pogodin, V. I. Dubovskaya, S. M. Ivanov, O. A. Tarasova, K. A. Murtazalieva, M. I. Semin, I. S. Maiorov, A. S. Gaur, G. N. Sastry, and V. V. Poroikov "Computational platform Way2Drug: from the prediction of biological activity to drug repurposing" (review)

- V. V. Emel'yanov, A. V. Ivanov, E. A. Savateeva, L. P. Sidorova, T. A. Tseitler, I. F. Gette, T. S. Bulavintseva, I. G. Danilova, N. E. Maksimova, N. N. Mochul'skaya, O. N. Chupakhin, and V. A. Chereshnev "Structureactivity relationship in the series of 1,3,4-6H-thiadiazines correcting metabolic disorders in experimental diabetes mellitus"

- A. V. Sulimov, D. C. Kutov, E. V. Katkova, O. A. Kondakova, and V. B. Sulimov "Search for approaches to improving the calculation accuracy of the protein-ligand binding energy by docking"

- E. V. Tutubalina, Z. Sh. Miftakhutdinov, R. I. Nugmanov, T. I. Madzhidov, S. I. Nikolenko, I. S. Alimova, and A. E. Tropsha "Identification of drugs with similar therapeutic actions on the basis of semantic text analysis"

- N. R. Khafizov, T. I. Madzhidov, O. N. Kadkin, and I. S. Antipin "On exchange interaction mechanisms in the $N, N^{\prime}$-dioxyl-1,3,5,7-tetramwthyl-2,6-diazaadamantane biradical" 